\title{
Correspondence
}

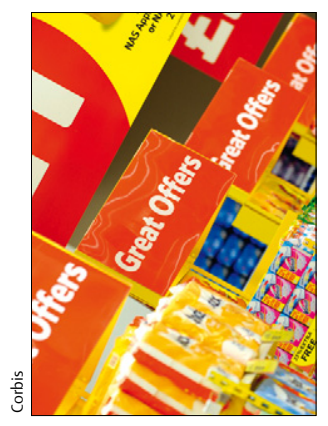

regarded as a conflict of interest in any legal definition. Moreover, being Minister of Health of a great country such as Iran is not a secret.

Although we are proud of giving service in the Ministry of Health (KBL as minister 2005-09; SMA as deputy 2005-08), we do not consider the implementation of the Family Physician Project as a personal activity. Indeed this programme was started in April, 2005, after approval by Parliament in February, 2005, months before the appointment of KBL as Minister in August, 2005. Many people in the Ministries of Health and Welfare of Iran worked with great enthusiasm to implement this major reform, including more than 30000 Behvarz (health workers) and more than 10000 physicians and midwives.

$\mathrm{KBL}$ helped to establish and run this national project and was completely immersed in it. This close involvement is what permitted us to make comments on the project. When we saw the letter by Shalileh and Mahdanian, ${ }^{1}$ we thought health researchers should be aware of both the advantages and disadvantages of the programme, to show both sides of the coin. The main message of our letter was that, although the Family Physician Project has seen many difficulties during implementation, it has had a measurable positive effect on health outcomes. Undoubtedly many more things need to be done to better implement this programme, but Parliament has once again included it in its latest national strategic programme for development, implying that Parliament was convinced by the project's progress. This programme, along with the expansion of the referral system, should be the main strategy of the Ministry of Health, and the Government as a whole, in health-sector reform.

Finally, we would like to highlight our hearty respect for ethical issues such as declaring any types of conflict of interest; however, on the basis of our best judgment at the time, there was no conflict of interest in our previous letter. We might have different views but this should not influence our scientific activities and our judgments.

KBL was Minister of Health of Iran between 2005 and 2009. SMA was Deputy Minister of Health between 2005 and 2008. Both were involved in the establishment and running of the Family Physician Project, but are not in administrative or executive positions now. AAH has no conflicts of interest.

*Kamran Bagheri Lankarani, Sayed Moayed Alavian, Ali Akbar Haghdoost lankaran@sums.ac.ir

Shiraz University of Medical Sciences, Health Policy Research Center, Shiraz, Fars 71348, Iran (KBL); Baghiatellah University of Medical Sciences, Tehran, Iran (SMA); and Kerman University of Medical Sciences, Kerman, Iran (AAH)

1 Shalileh K, Mahdanian A. Family physicians' satisfaction in Iran: a long path ahead. Lancet 2010; 376: 515

\section{Two important issues when promoting healthier food}

In discussing strategies to combat cardiovascular disease worldwide, Sonia Anand and Salim Yusuf (Feb 12, p 529) ${ }^{1}$ rightly point to the complex socioeconomic interactions that need to be considered when promoting healthy food consumption. However, details of these interactions are left implicit. Two important issues that must be dealt with in any strategy are highlighted here.

First, a focus on health alone is too narrow. Attention must be paid to other meanings attributed to food by different consumers. ${ }^{2}$ Food is not only fuel for the body; consuming food is also an enjoyable experience. Further, food expresses social values and cultural identity. For example, to show their hospitability at dinner parties, hosts often present their guests with an abundance of unhealthy but enjoyable foods. Meanings greatly affect consumption, but they vary between different subgroups. To deal with these differences, a segmented marketing approach is required.

Second, research has shown that consumers often value short-term consequences, such as price and instant gratification, over long-term consequences, such as health issues. ${ }^{3}$ A consequence for the food market is that supply-side and demand side hold each other in a "lock-in". The demand-side overconsumes unhealthy, cheap food products, and the supply-side fulfils market demand. The importance of price and gratification forces suppliers to offer low-priced products through economies of scale. This ensures that many innovative healthy, but more expensive, alternatives cannot compete and that the lock-in is maintained. This lock-in can only be broken if policy targets supply and demand in a coordinated way. ${ }^{4}$

I declare that I have no conflicts of interest.

FrankJ van Rijnsoever f.vanrijnsoever@geo.uu.nl

Innovation Studies, Copernicus Institute of Sustainable Development, Utrecht University, 3584 CS Utrecht, Netherlands

1 Anand SS, Yusuf S. Stemming the global tsunami of cardiovascular disease. Lancet 2011; 377: 529-32.

2 Korthals M. Before dinner: philisophy and ethics of food. Amsterdam: Boom, 2002.

3 Hoch SJ, Loewenstein GF. Time-inconsistent preferences and consumer self-control. J Consumer Res 1991; 17: 492-507.

4 Smits REHM, Kuhlmann S. The rise of systemic instruments in innovation policy. Int J Foresight Innovation Policy 2004; 1: 4-32. 